\title{
INFLUENCIA DA VELOCIDADE DE ASCENSÃO DAS MICROBOLHAS EM UMA CÂMARA DE FAD
}

\author{
R. S. VASCONCELOS ${ }^{1,3}$, R. C. S. HENAUTH ${ }^{1,3}$, A. E. MOURA ${ }^{2,3}$, L. A. SARUBBO ${ }^{1,3}$ e V. A. \\ SANTOS $^{1,3}$ \\ ${ }^{1}$ Universidade Católica de Pernambuco, Centro de Ciência e Tecnologia; \\ ${ }^{2}$ Universidade Federal de Pernambuco, Departamento de Energia Nuclear; \\ ${ }^{3}$ Centro de Gestão de Tecnologia e Inovação (CGTI) \\ E-mail para contato: robsonsv12@yahoo.com.br
}

\begin{abstract}
RESUMO - No laboratório ou em escala piloto tem-se realizado um esforço significativo para descrever e modelar um scale-up para o processo de flotação por ar dissolvido (FAD). No presente trabalho foram realizadas medidas da velocidade de ascensão de microbolhas em uma câmara de flotação de uma unidade piloto de FAD. As medidas foram realizadas, em condições otimizadas de operação, com auxílio de uma máquina fotográfica marca SONY, modelo DSC-W620. Foram desenvolvidas correlações de scale-up com base na análise dimensional do fenômeno. A validação das referidas correlações dependem da velocidade de ascensão dos flocos. A determinação da velocidade de ascensão das microbolhas, cujas dimensões são menores que às dos flocos (gota de óleo envolvido por microbolhas), permitiu o desenvolvimento de uma técnica simples, de baixo custo e a percepção de que uma maior retenção devido a uma menor velocidade de ascensão das microbolhas (tempo de residência), leva a uma maior eficiência para o processo de flotação.
\end{abstract}

\section{INTRODUÇÃO}

A flotação por ar dissolvido (FAD) é um processo de separação físico-químico que emprega bolhas de gás para diminuir a densidade média das partículas de forma que elas subam à superfície da lamina líquida, onde serão removidas. Para cada caso em particular, existem condições ótimas de formação de flocos e de geração de microbolhas que garantem o máximo de desempenho associado ao menor custo (SANTOS et al., 2004).

O tamanho das bolhas é um dos principais aspectos que deve ser considerado no sistema de flotação, sendo mais adequadas as bolhas menores, uma vez que elas deslocam menos líquido da superfície das partículas às quais se aderem e por isso apresentam maior facilidade de adesão 
com as impurezas. Adicionalmente, a velocidade terminal de ascensão das bolhas, que pode ser estimada pela Equação 1 quando se considera o líquido em repouso e bolhas com diâmetro inferior a $140 \mu \mathrm{m}$, é influenciada pelo tamanho delas. Bolhas menores apresentam menor velocidade ascensional, de modo que resulta maior tempo de detenção e, consequentemente, maior oportunidade de contato com as partículas a serem removidas (PÁDUA et al., 1999).

$$
V_{a}=\frac{g \cdot d_{b}{ }^{2}}{18 \cdot \gamma}
$$

Em que:

$V_{a}:$ velocidade ascensional da bolha [m.s]

$g:$ aceleração da gravidade $\left[\mathrm{m} . \mathrm{s}^{-2}\right]$

$d_{b}:$ diâmetro da bolha $[\mathrm{m}]$

$\gamma$ : viscosidade cinemática do líquido $\left[\mathrm{m}^{2} . \mathrm{s}\right]$

O sucesso, das instalações industriais, depende substancialmente das bases, consideradas no scale-up e do projeto do equipamento. Trivedi e Shah (2012) definem scale-up como um processo de aplicação do mesmo sistema para diferentes volumes de produção. Com as adoções de um protótipo em escala piloto e da metodologia de flotação por ar dissolvido (FAD) na separação e recuperação de águas oleosas, existe a necessidade de se elaborar e validar um modelo de previsão de scale-up para promover a mudança de escala necessária (ZLOKARNIK, 2006). O primeiro passo consiste na realização de testes em uma unidade piloto que permita avaliar as condições operacionais (OLIVEIRA e AQUINO, 2006). O scale-up é o processo pelo qual os resultados obtidos em equipamento de pequena escala são utilizados para conceber um equipamento de grandes dimensões. Na flotação, o objetivo desse aumento de escala é, geralmente, para alcançar a mesma resposta da flotação, que ocorre em pequena escala, para aquela que ocorre em grande escala (NEWELL e GRANO, 2007).

$\mathrm{Na}$ sedimentação, a força de gravidade faz com que as partículas presentes na água se depositem no fundo do decantador. Na flotação a clarificação é conseguida por meio da produção de (micro) bolhas que se aderem aos flocos ou partículas em suspensão, aumentando-lhes o empuxo e provocando sua ascensão até a superfície do flotador, de onde são removidas (PÁDUA et al., 1999). O principal objetivo do presente trabalho foi avaliar a influência da velocidade de ascensão de microbolhas, na formação de flocos, numa câmara de flotação por ar dissolvido (FAD). Nos ensaios realizados numa unidade piloto de flotação foram estudados os parâmetros relevantes da velocidade terminal de ascensão das microbolhas, com o intuito de testar um método de determinação de velocidade de microbolhas e flocos. 


\section{METODOLOGIA}

O protótipo de flotação por ar dissolvido (FAD), em escala piloto, por operar em temperatura e pressão ambiente, foi confeccionado em acrílico incolor e transparente para permitir a visualização de boa parte dos fenômenos fluidodinâmicos (KNOWLTON, 2000). O conjunto de FAD, cujo esquema da disposição dos componentes, pode ser visualizado na Figura 1, é composto por duas câmaras de flotação dispostas em série, que sequenciam antecâmaras e processam o afluente, o qual entra em contato com um fluxo de microbolhas em cada uma das câmaras.

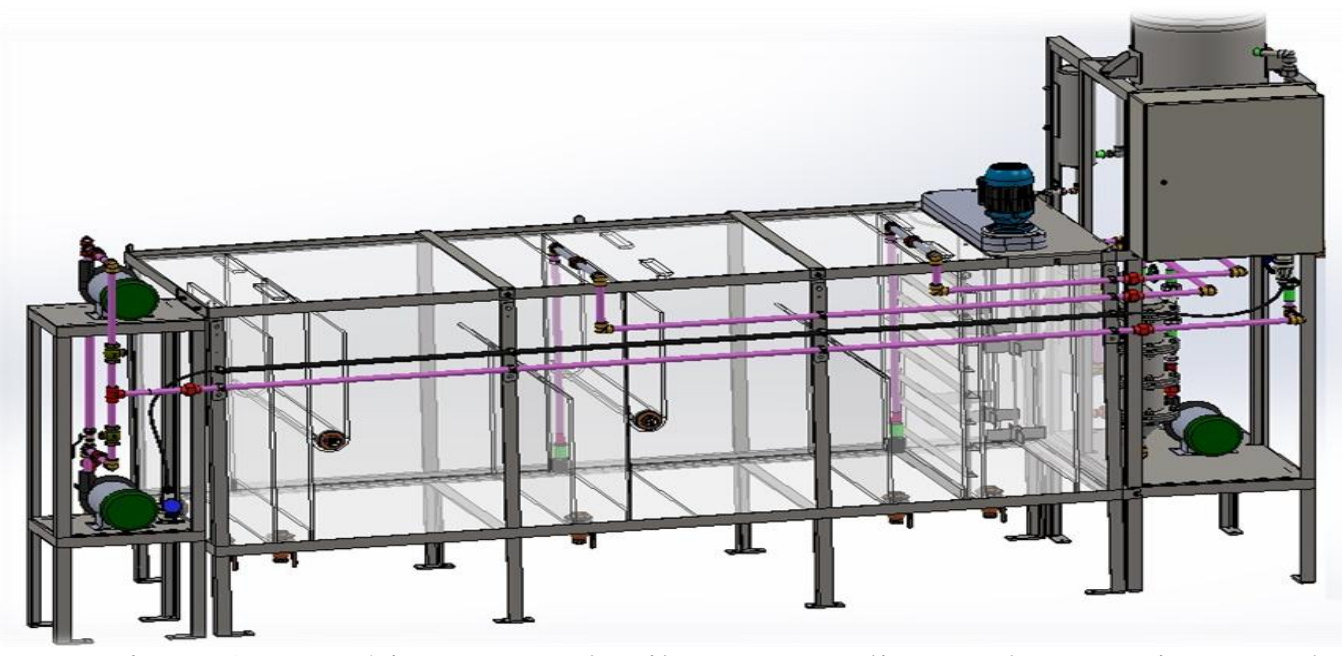

Figura 1 - Protótipo em escala piloto para realização dos experimentos da FAD.

$\mathrm{Na}$ altura de $7 \mathrm{~cm}$, partindo da base da célula de flotação foi posicionada uma câmera filmadora marca SONY, modelo DSC-W620 (com foco ajustado), que tem um modo de gravação de alta velocidade com a capacidade de gerar vídeos a uma taxa de aquisição em torno de 120 quadros por segundo. Foram feitas marcações de $4 \mathrm{~cm}$ na tubulação de onde saiam as microbolhas. Estas ascenderam e passaram pelas referidas marcações, sendo seu trajeto capturado pela filmadora. Algumas microbolhas aglomeraram-se à partículas oleosas, formando um agregado (floco), que ascendia com uma velocidade diferente da velocidade das microbolhas. Os vídeos obtidos pela câmera filmadora foram tratados utilizando o software Windows Media Player, disponível gratuitamente na internet. Este possibilitou a passagem da filmagem quadro a quadro e a identificação dos flocos e microbolhas, como mostra a Figura 1, favorecendo a aferição do tempo gasto pelas microbolhas e flocos que deslocaram-se pelas marcações e, desta forma, de posse do tempo e da distância, foi permitida a realização do cálculo da velocidade de ascensão. 


\section{RESULTADOS}

Através de gráficos do tipo Box plot, foi possível avaliar a distribuição empírica dos dados. Com esse tipo de gráfico pôde-se observar como os valores de velocidade de ascensão das microbolhas estão distribuídos. Valores de tendência central (mediana), valores máximos e mínimos e valores atípicos (outliers) se existirem. A Figura 2 mostra o comportamento da caixa mediana (Box) com uma distribuição homogênea, no que diz respeito às velocidades das microbolhas. A distribuição dos dados apresenta-se simétrica, visto que o ponto que representa a mediana está localizado no centro da caixa, não existindo outliers, ou seja, valores discrepantes para mais ou para menos. Uma distribuição normal dos valores medidos, dentro de um intervalo de confiança de $95 \%$ forneceu um valor de velocidade média de ascensão para as microbolhas em torno de $8,73 \cdot 10^{-7} \mathrm{~m} / \mathrm{s}$, com previsões de velocidades que vão de $8,51 \cdot 10^{-7} \mathrm{~m} / \mathrm{s}$ a $8,95 \cdot 10^{-7}$ $\mathrm{m} / \mathrm{s}$.

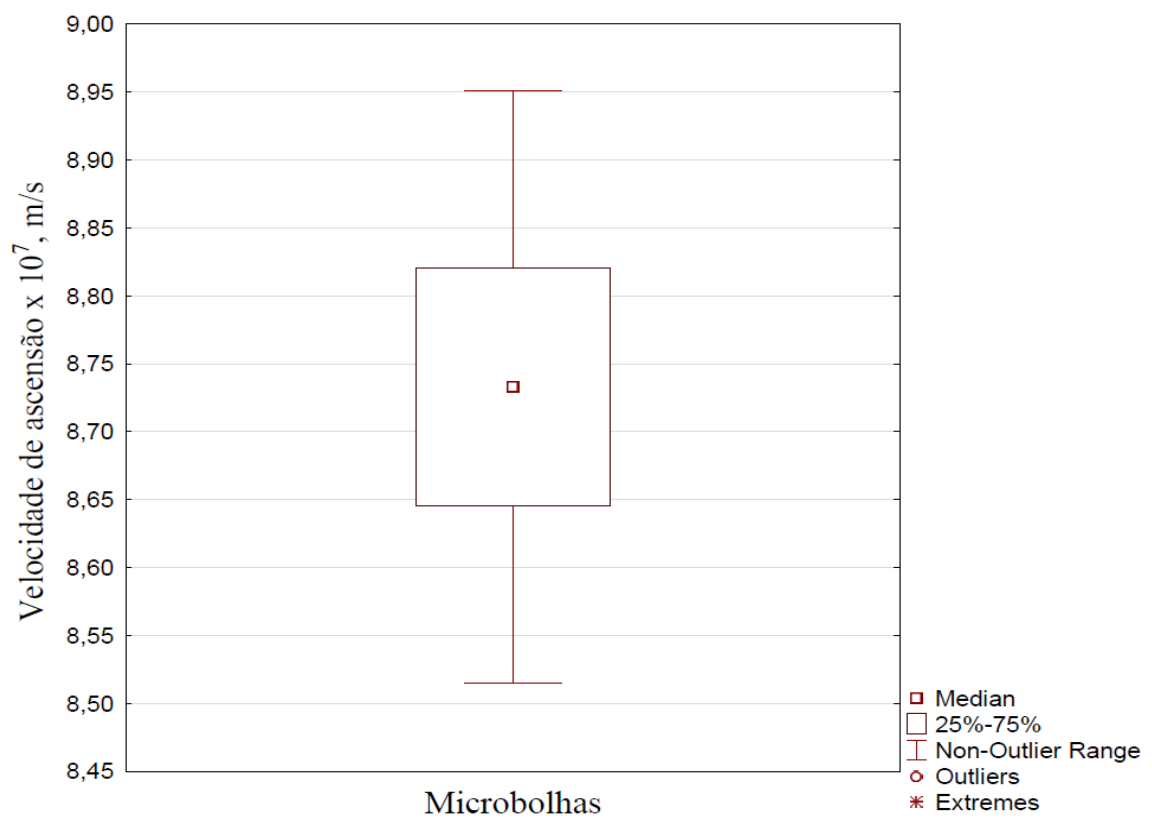

Figura 2 - Desenho esquemático em duas dimensões para as microbolhas.

O gráfico que ilustra a análise estatística dos valores de velocidade de ascensão dos flocos (Box plot) é apresentado na Figura 3. Novamente obteve-se dados com uma distribuição simétrica, onde não existe previsão para outliers. A velocidade média computada para um intervalo de confiança de $95 \%$ ficou em torno de $1,175 \cdot 10^{-5} \mathrm{~m} / \mathrm{s}$, com valores mínimos e 
máximos que vão de $1,132 \cdot 10^{-5} \mathrm{~m} / \mathrm{s}$ a $1,216 \cdot 10^{-5} \mathrm{~m} / \mathrm{s}$, respectivamente.

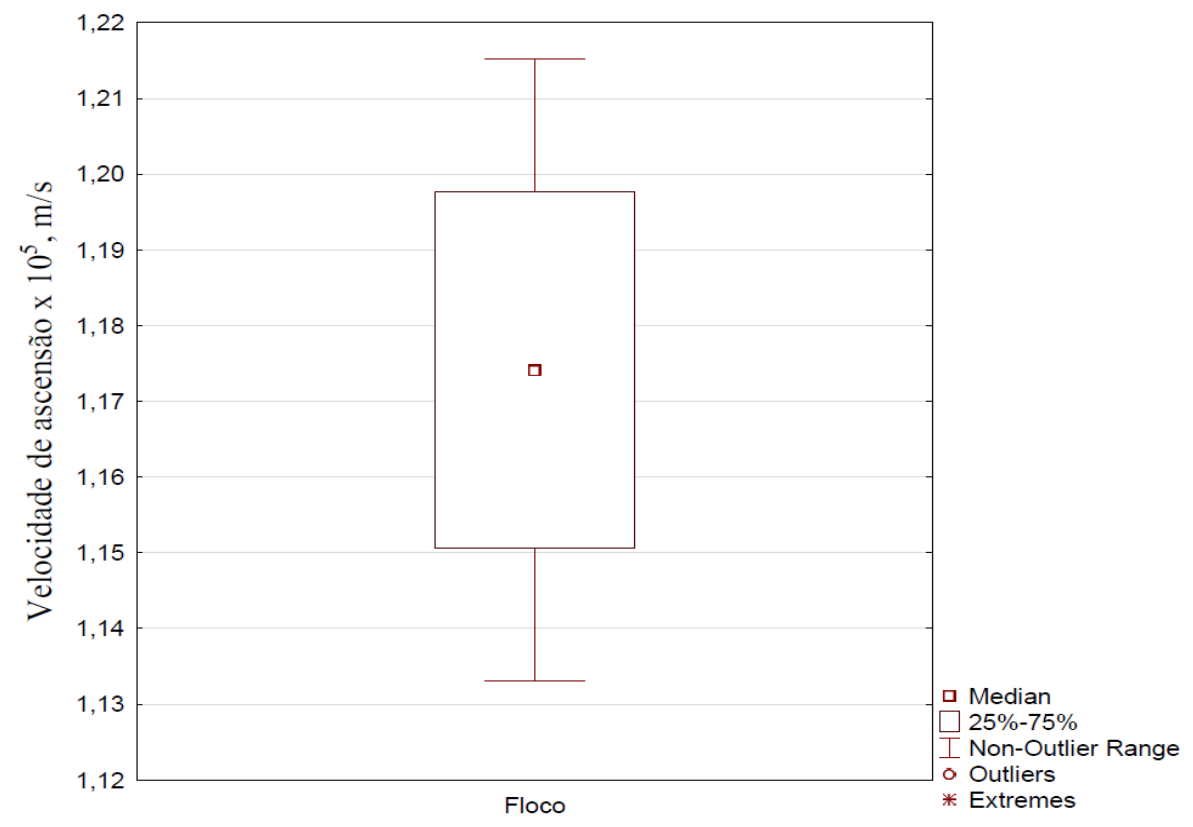

Figura 3 - Desenho esquemático em duas dimensões para os flocos.

Observa-se nas Figuras 1 e 2 uma nítida diferença entre as velocidades médias das microbolhas e dos flocos, sendo a primeira da ordem de 13 vezes. Observa-se ainda que os valores máximos e mínimos de ambas as faixas de velocidades encontram-se em regiões de valores bastante diferenciados. Isto reforça que após a formação de um floco, aglomeração de microbolhas em uma gota de óleo, com a estrutura final de dimensões bem maiores que a de uma microbolhas, a velocidade da estrutura final obedece à lei prevista pela Equação 1. Uma maior dimensão para o diâmetro de um floco, associada aos efeitos de arrasto da fase contínua (aquosa) contribuem para esse aumento de velocidade.

\section{CONCLUSÕES}

Com a técnica de medidas de velocidade de ascensão desenvolvida, para microbolhas e flocos, pôde-se validar experimentalmente modelos propostos na literatura que permitiram concluir a grande influência das baixas velocidades das microbolhas $\left(10^{-7}\right)$ comparadas às dos flocos $\left(10^{-5}\right)$. O método experimental caracterizou-se pela simplicidade e baixo custo, além de permitir uma comparação precisa entre as diferentes velocidades. 


\section{AGRADECIMENTOS}

À FACEPE, pela concessão da bolsa de Mestrado, ao Centro de Gestão de Tecnologia e Inovação (CGTI) pelo apoio técnico concedido e à UNICAP, pela oportunidade de realização do Mestrado.

\section{REFERÊNCIAS}

BORTOLOZO, J. P. Estudo Experimental e Modelagem da Velocidade Terminal de Partículas em Colunas de Bolhas. 2010. 187p. Dissertação (Mestrado em Engenharia) - Universidade Federal do Paraná, Curitiba. 2010.

KNOWLTON, T. M. Tools And Techniques For Diagnosing And Solving Operating Problems in Fluidized Bed Systems. Oil Gas Sci Tech J. - Rev. IFP, v. 55, n. 2, p. 209 - 217, 2000.

MORUZZI, R. B.; REALI, M, A. P. Characterization of Micro-Bubbles Sizes Distribution in DAF Contact Zone by a Non-Intrusive Image Analysis System. In: The $5^{\text {th }}$ International Conference on Flotation in Water in Wastewater Systems, Seul, Korea, 2007.

NEWELL, R.; GRANO, S. Hydrodynamics and Scale-up in Rushton Turbine Flotation Cells: Part 1 - Cell Hydrodynamics. Int. J. Miner. Process., n. 81. p. 224 - 236. 2007.

OLIVEIRA, M. L. M.; AQUINO, J. A. Aspectos Relevantes das Colunas de Flotação. Holos Environ., Ano 22, p. 44 - 52, 2006.

PÁDUA, V. L.; SALES, M. V.; FREIRE, R. E. Influência do Pré-Tratamento Químico no Desempenho de Unidades de Flotofiltração e de Filtração Direta Descendente. In: $21^{\circ}$ Congresso Brasileiro de Engenharia Sanitária e Ambiental, Jõao Pessoa, Paraíba. 2001.

SANTOS, H. R.; PRADO, G. S.; VIDAL, C. M. S.; MORUZZI, R. B.; CAMPOS, J. R. Aplicabilidade das Técnicas de Determinação de Tamanho de Partículas em Sistemas de Tratamento de Água e Esgoto Sanitário. Eng. Sanit. Ambient., Rio de Janeiro, v. 9, n. 4, 2004.

SIQUEIRA, B. A.; BARBOSA, J. L. F.; SILVA, D. D.; ALMEIRA, R. G.; SILVA, M. O. Análise de Técnica de Sensores Duplos de Condutividade Para Obtenção da Velocidade de Bolhas Usando Filmagem. In: XL Congresso Brasileiro de Educação em Engenharia 
(COBENGE), Belém do Pará, 2012.

TRIVEDI, B.; SHAH, B. H. Scale-up of API. Int. J. Sci. Eng. Tech., v. 1, n. 2, p. 190 - 196, 2012.

ZLOKARNIK, V. M. Dimensional Analysis and Scale-up in Chemical Engineering. Berlim: Wiley, 296p. 2006. 